\title{
Elementos para uma Intervenção em Aconselhamento Psicológico com Pais Enlutados
}

\author{
Ana Bárbara Morelli \\ Fabio Scorsolini-Comin \\ Universidade Federal do Triângulo Mineiro \\ Uberaba, $M G$, Brasil \\ Manoel Antônio dos Santos \\ Universidade de São Paulo \\ Ribeirão Preto, SP, Brasil
}

\begin{abstract}
RESUMO
Este estudo teve por objetivo delinear os principais elementos que devem compor um programa de intervenção em aconselhamento psicológico com pais enlutados, a partir das necessidades de casais que perderam seus filhos. Trata-se de um estudo de caso coletivo desenvolvido com cinco casais, que foram entrevistados individualmente e, em seguida, em díades, totalizando 15 entrevistas. Os resultados permitiram a construção de três categorias, que constituem os elementos centrais a serem considerados na proposição de um programa de aconselhamento psicológico: (1) necessidade de acolhimento emergencial do sofrimento, (2) conjugalidade e (3) espiritualidade/religiosidade. Com base na experiência dos pais investigados, recomenda-se disponibilizar intervenções individuais, na estratégia de atendimento breve, ou de casal, com foco no acolhimento e potencialização de recursos adaptativos advindos da conjugalidade e da prática espiritual/religiosa.
\end{abstract}

Palavras-chave: Conjugalidade; Luto; Intervenções psicológicas; Aconselhamento psicológico.

\begin{abstract}
Elements for an Intervention in Counseling Psychology with Bereaved Parents

This study aimed to list the main elements that compose a program of interventions in Counseling Psychology to bereaved parents, from the needs of couples who lost their children. It is a collective case study developed with five couples who were interviewed individually and then in pairs, totaling 15 interviews. The results allowed the construction of three categories, which are the key elements to be considered in proposing a program of Counseling Psychology: (1) the need for emergency care of suffering, (2) marital relationships and (3) spiritually/religiosity. Based on the experience of the parents surveyed, it is recommended to provide individual brief interventions, or in couple, with a focus on reception and promotion of adaptive resources arising from marital relationships and spiritual/ religious practice.
\end{abstract}

Keywords: Marital relationships; Grief; Psychological interventions; Counseling psychology.

\section{RESUMEN}

Elementos para una Intervención en Consejería Psicológica con los Padres en Duelo

Este trabajo objetivó describir los principales elementos que componen un programa de consejería de intervención para padres en luto, partiéndose de las necesidades de las parejas que han perdido a sus hijos. Es un estudio de caso colectivo, desarrollado con cinco parejas que fueron entrevistados individualmente y en pares, en un total de 15 entrevistas. Los resultados permitieron la construcción de tres categorías, que son los elementos clave a tener en cuenta en la propuesta de un programa de asesoramiento psicológico: (1) la necesidad de atención de emergencia de sufrimiento, (2) marital y (3) la espiritualidad/religiosidad. Basándose en la experiencia de los padres encuestados, se recomienda realizar intervenciones individuales, o en parejas, la estrategia de pronta atención, con un enfoque en la recepción y la potenciación de los recursos de adaptación derivados de la conyugalidad y espiritualidad/religiosidad. Palabras clave: Conyugalidad; El duelo; Las intervenciones psicológicas; Orientación psicológica. 
O processo de enlutamento tem sido um tema caro à Psicologia ao longo das últimas décadas. Bowlby (1985) aponta que vários aspectos influenciam no desenvolvimento do luto, inclusive as condições circunstanciais da perda e condições psicológicas do enlutado. Diante da dor deflagrada pela situação de crise, impõe-se a necessidade de uma reorganização do indivíduo no mundo e também nas suas relações, que se encontram fragilizadas nesse momento. Segundo Gonçalves (2001), o luto também dependerá da ajuda recebida, ou seja, das fontes de apoio social, dentre as quais situam-se as de origem familiar. A depender do modo como é experienciado, o luto pode gerar conflitos conjugais (Morelli, Scorsolini-Comin, \& Santos, 2013), motivo pelo qual estudos têm investigado a experiência do luto em casais que perderam seus filhos (Bittencourt, Quintana, \& Velho, 2011).

O modo como o casal experiencia a parentalidade também interfere na dinâmica matrimonial, podendo aproximar os genitores ou causar maior distanciamento após a experiência de perda (Féres-Carneiro, 1998; Magagnin et al., 2003; Menezes \& Lopes, 2007; Scorsolini-Comin \& Santos, 2011). Na perspectiva psicanalítica, Freud (1914/1976) destaca que, a partir do nascimento do filho, os genitores resgatam seu narcisismo infantil perdido, ou seja, tentam recuperar o que outrora desejavam e que não puderam alcançar. Desenham um plano de vida para o filho em que não há espaço para a presença de impedimentos para a felicidade, sendo que a realização do filho pode se tornar uma das metas vitais dos genitores. Quando um empecilho surge no decorrer do caminho, como a doença grave ou a morte, abre-se uma ferida narcísica no ego dos pais, uma vez que eles podem se identificar com o filho perdido (Monti, 2008).

Quando não elaborado, o luto pode desencadear prejuízos psíquicos, sociais e emocionais, levando à necessidade de intervenções que atendam à demanda emocional dos casais que perderam seus filhos. É nesse sentido que alguns programas têm sido delineados como estratégia de fornecimento de suporte, orientação e acompanhamento para pessoas que experienciam o luto (Kovács, 1992, 2012; Pascoal, 2012; Sandler et al., 2003; Santos \& Sales, 2011; Souza, Moura, \& Corrêa, 2009), inclusive com casais (Silva \& Nardi, 2010). Alguns desses programas sustentam-se na oferta de psicoterapia, que se baseia, em linhas gerais, na possibilidade de que, a partir de um processo de construção e reconstrução de sentidos sobre vínculos, solidão, saudade e enfrentamento, as pessoas possam narrar suas experiências de modo a enfatizar o processo de transformação de si a partir do enlutamento decorrente da perda de um ente próximo (Alves,
Fernández-Navarro, Ribeiro, Ribeiro, \& Gonçalves, 2014). Estes autores, no contexto português, destacam a necessidade de investimento na relação entre terapeuta e cliente, de modo que o profissional possa desenvolver maior empatia com a pessoa em sofrimento e com dificuldades no manejo da experiência de perda de alguém afetivamente próximo.

No Brasil ainda são poucos os programas de atendimento voltados especificamente a pacientes enlutados ou, ainda, esse tipo de intervenção não tem sido investigada e divulgada sistematicamente nos meios acadêmicos (Bolze \& Castoldi, 2005; Muza, Sousa, Arrais, \& Iaconelli, 2013). No entanto, é possível que sejam construídas alternativas viáveis que atendam à demanda dos familiares que perderam um de seus entes queridos, pois "o sofrimento trazido pela morte do outro pode ser o início de um amadurecimento emocional e o trabalho psicológico vem para auxiliar na construção desta nova realidade" (Pascoal, 2012, p. 729). Aponta-se, desse modo, para a necessidade de se conhecer como são desenvolvidas essas intervenções no processo de enlutamento, seus pressupostos e resultados, a fim de que outros modelos possam ser propostos. Avaliar os programas existentes também é uma forma de aprimorar as intervenções, a fim de que estas alcancem os objetivos propostos (Muza et al., 2013; Sandler et al., 2003).

Uma das modalidades que podem ser empregadas no atendimento a pessoas enlutadas é o aconselhamento psicológico, que consiste em um processo estruturado de ajuda a partir do relacionamento estabelecido entre o conselheiro e a pessoa em busca de ajuda (Forghieri, 2007; Morato, 1999). Por meio do diálogo e da consideração positiva acerca daquele que busca auxílio, conselheiro e cliente desenvolvem uma relação na qual o profissional ajuda o outro a tomar consciência de si, de esclarecimento de sua queixa, suas limitações e potencialidades. Trata-se de uma modalidade diferente da psicoterapia, embora apresente algumas semelhanças, como o acompanhamento do indivíduo em sofrimento ou que experimenta uma dificuldade, crise ou conflito (Santos, 1982; Scorsolini-Comin, 2014).

No caso do atendimento a pessoas enlutadas, o aconselhamento pode ser estruturado visando a atender a essa demanda específica, utilizando recursos para que os clientes desenvolvam estratégias de enfrentamento diante da situação de forte mobilização emocional deflagrada, como no caso da perda de um filho. Embora haja diferentes perspectivas teóricas no campo do aconselhamento psicológico, sendo a mais recorrente a abordagem centrada na pessoa, desenvolvida por Carl Rogers na segunda metade do século XX (Scorsolini-Comin \& Santos, 2013), o presente estudo 
não destacará questões particulares de uma dada abordagem em aconselhamento, mas de elementos que podem e devem atravessar toda intervenção nessa modalidade. Respaldamo-nos nas considerações de Schmidt (2012), de que a disponibilidade de escuta e a presença genuína do conselheiro são mais importantes para os resultados de uma intervenção do que o referencial de base adotado.

Desse modo, entendemos o aconselhamento psicológico como uma modalidade que envolve o acolhimento, a compreensão da queixa e o desenvolvimento, com o cliente, de estratégias para a resolução de problemas - no caso, com foco no processo de enlutamento. Pode ser desenvolvido de modo breve, em sessões estruturadas, voltadas para a superação do momento de crise e compreensão do processo de enlutamento. Caso o luto seja considerado patológico ou envolva sofrimento intenso, o profissional responsável pelos atendimentos pode encaminhar a pessoa para atendimento psicoterápico (Schmidt, 2012), a fim de aprofundar aspectos necessários para o enfrentamento do processo penoso.

Ainda são escassas as descrições de atendimentos realizados no contexto do aconselhamento psicológico com pessoas enlutadas, especificamente com casais que perderam os filhos (Bonanno, Moskowitz, Papa, \& Folkman, 2005; Scorsolini-Comin \& Santos, 2013), havendo a necessidade não apenas de conhecer essas intervenções, como avaliar a efetividade das mesmas (Currier, Neimeyer, \& Berman, 2008). Alguns estudos destacam o processo de enlutamento em pessoas que perderam seus cônjuges, ressaltando a possibilidade de manutenção de vínculos, o que envolve a revisão de relacionamentos e a reconstrução de significados sobre a identidade, a conjugalidade, a vida e a morte (Dennis \& Kunkel, 2012). Em um novo paradigma acerca do trabalho com o luto, estes autores destacam a necessidade de que se estabeleça um processo de comunicação em relação à morte e ao luto, para que as pessoas consigam desenvolver recursos para lidar com a perda. Não se trata, portanto, de encorajamento para que a pessoa lembre-se pouco do ente falecido, mas justamente o contrário, isto é, devem-se encontrar formas de falar a respeito da pessoa que se foi, por exemplo, por meio da redação de cartas e de comunicações sociais dirigidas à comunidade para produzir relatos acerca daquela perda. A estratégia consiste, sumariamente, em falar a respeito dessa dor, o que pode favorecer o processo de lidar melhor com tal evento estressor e, por vezes, traumático.

Em termos da efetividade das intervenções psicológicas voltadas às pessoas enlutadas, Currier et al. (2008) analisaram um vasto corpo de literatura, incluindo a eficácia das técnicas e as mudanças observadas ao longo do tempo pelas pessoas atendidas nesses programas. Tais intervenções tiveram um pequeno efeito no pós-tratamento, mas nenhum benefício estatisticamente significativo no follow-up, o que nos sugere a necessidade de que os atendimentos não ocorram somente imediatamente à perda, mas ao longo do processo de vivência e elaboração do luto desencadeado pela morte. No entanto, os autores apontaram que intervenções voltadas especificamente para os enlutados ofereceram benefícios semelhantes aos encontrados em psicoterapias para tratamento de outras dificuldades emocionais, reforçando a importância de prover esses atendimentos. Resultados positivos em intervenções com pais também foram relatados no estudo de Sandler et al. (2003), em um programa intitulado Family Bereavement Program (FBP). Tais intervenções promoveram mudanças nos pais, reduzindo os efeitos estressores da morte do familiar próximo. No follow-up, o FBP levou à redução de sintomas relacionados ao luto. O estudo de Larson e Hoyt (2007) também apresentou evidências que comprovam as intervenções psicológicas com enlutados na modalidade de aconselhamento.

Também se observa dificuldade de muitos profissionais de Psicologia em trabalharem com o luto em suas intervenções, haja vista que a morte ainda é concebida como um tabu (Ferreira, Lira, Siqueira, \& Queiroz, 2013). Na formação acadêmica dos psicólogos e dos demais profissionais de saúde, muitas vezes não há espaço disponível para que os estudantes reconheçam e elaborem seus sentimentos e experiências acerca da morte, do morrer e do luto. Formados nesse modelo e sob essas circunstâncias, alguns desses profissionais podem encontrar dificuldades de trabalhar com a temática, de modo que acabam automatizando conceitos, com pouco ou nenhum espaço para enfrentarem seus próprios limites e desafios diante da temática (Domingues et al., 2013; Muza et al., 2013; Souza et al., 2009). Assim, observase uma falta tanto de formação acadêmica adequada, quanto de aproximação prática com a área ou mesmo disponibilidade interna para entrar em contato com pessoas em sofrimento, por vezes, intenso e aflorado. No que tange à preparação desses profissionais, faz-se necessária uma discussão em torno de como poderia ocorrer essa formação, com destaque para técnicas, procedimentos clínicos e protocolos que poderiam auxiliar a atuação dos psicólogos engajados no aconselhamento em situação de luto.

Uma vez constatada essa lacuna e visando a ampliar a gama de possibilidades de enfrentamento do luto, este estudo teve por objetivo delinear os 
principais elementos que podem compor um programa de intervenção em aconselhamento psicológico com pais enlutados, a partir das necessidades relatadas por casais que perderam seus filhos.

\section{MÉTODO}

\section{Tipo de estudo (Delineamento) e cuidados éticos}

Trata-se um estudo de caso coletivo amparado na abordagem qualitativa, de corte transversal (Peres \& Santos, 2005). O estudo foi aprovado pelo Comitê de Ética em Pesquisa da instituição de origem dos autores (Protocolo 1938/2011).

\section{Participantes}

Participaram deste estudo cinco casais heterossexuais em união estável (consensual ou civil), maiores de idade e que perderam um filho havia, no mínimo, um ano. Não houve qualquer restrição quanto à condição socioeconômica, profissão/ ocupação, escolaridade, tempo máximo decorrido desde a morte do filho, tempo máximo de casamento e quantidade de filhos do casal. A Tabela 1 sumariza as principais características dos casais participantes e as circunstâncias/causas do falecimento dos filhos. Para preservar o anonimato dos participantes foram utilizados nomes fictícios.

Entre os participantes a média de idade dos homens é de 45,5 anos e das mulheres, 40,5. Os casais estão unidos há 21,5 anos, em média. A causa mortis mais comum do filho foi o acidente automobilístico (dois casos) e doença grave (dois casos). Todos os pares perderam filhos do sexo masculino. Nenhum casal recebeu auxílio profissional durante o enlutamento. Todos os participantes residem em cidades do interior do Estado de São Paulo.

Os participantes Fátima e Pedro (Casal 1) tiveram quatro filhos, o terceiro faleceu aos 19 anos de acidente automobilístico. O casal se preocupava muito com o filho em vida, especialmente a mãe, devido às "más companhias" com que ele andava e à suspeita de envolvimento com drogas. José e Maria (Casal 2) tiveram três filhos, perderam o caçula de 19 anos, atropelado por um caminhão. Residem com seus dois filhos e se mostram extremamente preocupados com eles. O casal 3 (Margarida e Bento) teve dois filhos, o primogênito é casado e o caçula faleceu de câncer aos 27 anos. Durante a entrevista Margarida evoca, diversas vezes, a dor que ainda sente pela perda do filho e ressalta como necessita de ajuda para superar o trauma. Os participantes Nayara e Tales (Casal 4) perderam os filhos (gêmeos) quando a mãe estava no quarto mês de gestação. Por ocasião da entrevista, Nayara encontrava-se grávida novamente. O casal 5 (Elisa e Carlos) teve dois filhos, a filha primogênita é casada e tem um filho. O filho mais novo do casal faleceu com 37 dias de vida por pneumonia. Carlos afirma ser muito apegado à filha primogênita, mas relatou a dor da perda do filho. Elisa relata não entender porque a filha, que nasceu doente, está viva até hoje, enquanto que o filho, que nasceu aparentemente saudável, morreu precocemente.

\section{Instrumentos}

Em um primeiro momento foi utilizada a técnica da história de vida do participante (Meihy \& Holanda, 2010). Posteriormente, aplicou-se um

TABELA 1

Caracterização dos participantes segundo idade, profissão/ocupação, escolaridade tempo de casamento, motivo da morte do filho e idade do filho falecido $(n=10)$

\begin{tabular}{|c|c|c|c|c|c|c|c|}
\hline Casal & $\operatorname{Esposo}(a)$ & $\begin{array}{l}\text { Idade } \\
\text { (anos) }\end{array}$ & Profissão/Ocupação & Escolaridade & $\begin{array}{c}\text { Tempo de } \\
\text { casamento } \\
\text { (anos) }\end{array}$ & $\begin{array}{c}\text { Motivo da morte } \\
\text { do filho }\end{array}$ & $\begin{array}{l}\text { Idade do filho } \\
\text { falecido (anos) }\end{array}$ \\
\hline \multirow[t]{2}{*}{1} & Fátima & 50 & Faxineira & \multirow{2}{*}{ Ensino Fundamental } & \multirow{2}{*}{33} & Acidente & \multirow{2}{*}{19} \\
\hline & Pedro & 53 & Zelador & & & automobilístico & \\
\hline \multirow[t]{2}{*}{2} & Maria & 58 & Aposentado & \multirow{2}{*}{$\begin{array}{l}\text { Superior incompleto } \\
\text { Ensino Médio }\end{array}$} & \multirow{2}{*}{34} & Acidente & \multirow{2}{*}{19} \\
\hline & José & 66 & Aposentado & & & automobilístico & \\
\hline \multirow[t]{2}{*}{3} & Margarida & 57 & Dona de casa & \multirow{2}{*}{ Ensino Fundamental } & \multirow{2}{*}{39} & \multirow{2}{*}{ Câncer } & \multirow{2}{*}{27} \\
\hline & Bento & 63 & Aposentado & & & & \\
\hline \multirow[t]{2}{*}{4} & Nayara & 23 & Bordadeira & \multirow{2}{*}{$\begin{array}{c}\text { Ensino Médio } \\
\text { Ensino Fundamental }\end{array}$} & \multirow{2}{*}{4} & \multirow{2}{*}{$\begin{array}{l}\text { Interrupção } \\
\text { involuntária }\end{array}$} & \multirow{2}{*}{$3^{\circ}$ mês de gestação } \\
\hline & Tales & 25 & Avicultor & & & & \\
\hline \multirow[t]{2}{*}{5} & Elisa & 49 & Dona de casa & \multirow{2}{*}{ Ensino Fundamental } & \multirow{2}{*}{28} & \multirow{2}{*}{ Pneumonia } & \multirow{2}{*}{37 dias de vida } \\
\hline & Carlos & 48 & Operador de torno & & & & \\
\hline
\end{tabular}


roteiro de entrevista semiestruturado desenvolvido especificamente para este estudo, contendo questões disparadoras que exploravam a experiência da perda do filho e sua repercussão para a família e o casal.

\section{Coleta de dados}

O recrutamento dos participantes foi realizado por meio da rede de contatos dos pesquisadores. $\mathrm{O}$ primeiro contato foi estabelecido por telefone, quando se efetivava o convite para participação no estudo. Após a aceitação, um encontro era marcado para uma apresentação mais detalhada dos objetivos e procedimentos da pesquisa, mediada pela leitura e assinatura do Termo de Consentimento Livre e Esclarecido. Esses encontros e as entrevistas ocorreram nas residências dos casais, onde os cônjuges foram entrevistados individualmente, em um primeiro momento e, posteriormente, em dupla. Desse modo, foram realizadas 15 entrevistas com os cinco casais (10 individuais e cinco em díades). As entrevistas ocorreram face a face e foram audiogravadas, mediante aquiescência dos participantes.

\section{Análise dos dados}

Posteriormente, foi feita uma transcrição literal e na íntegra dos relatos obtidos. O material transcrito foi analisado a partir de duas estratégias, contemplando uma leitura vertical (análise individual) e outra, horizontal (cotejando todas as entrevistas), para o estabelecimento de categorias temáticas. Desse modo, com apoio da análise de conteúdo temática (Minayo, 2006), foi possível destacar pontos de convergência e divergência entre os relatos dos participantes acerca da experiência de luto, bem como lançar um olhar analítico sobre o corpus de pesquisa a partir do diálogo estabelecido com a literatura tanto da área do luto, quanto do aconselhamento (Kovács, 2005; Moratto, 1999; Muza et al., 2013; Schmidt, 2012; Scorsolini-Comin \& Santos, 2013; Souza et al., 2009). Após minuciosa análise, foram delineados principais elementos que emergiram dos relatos dos pais como potenciais marcadores de necessidades, que devem ser consideradas na proposta de um programa de intervenção em aconselhamento psicológico com casais enlutados.

\section{RESULTADOS E DISCUSSÃO}

Os resultados permitiram a construção de três categorias a serem consideradas na proposição de um programa de aconselhamento psicológico: (1) necessidade de acolhimento emergencial do sofrimento, (2) conjugalidade e (3) religiosidade.

\section{Categoria 1: Necessidade de acolhimento emergencial do sofrimento}

Alguns dos elementos principais mencionados pelos casais no processo de elaboração do luto permitem delinear os contornos de uma possível intervenção psicológica. Constituem, assim, elementos valiosos para o planejamento de uma intervenção em aconselhamento psicológico, obtidos a partir dos relatos dos casais e do cotejo com a literatura produzida na área. A escolha do aconselhamento psicológico também responde à necessidade de oferecer uma modalidade de escuta que não se restrinja essencialmente às características de um atendimento psicoterápico clássico, mas que contemple a tentativa de modificar a visão do psicólogo clínico no sentido de criar espaços de maior continência para as diferentes demandas de ajuda psicológica apresentadas pelas pessoas (Schmidt, 2012).

Primeiramente, há que se considerar que esses casais não receberam qualquer apoio psicológico, nem mesmo no caso em que o filho adoeceu gravemente por câncer e que havia, no contexto assistencial, disponibilidade de profissionais capacitados para proporem uma intervenção (Casal 3). O acompanhante do filho - no caso, o pai, não expressou sua necessidade de ser ouvido em sua dor, haja vista que sempre considerou que o sofrimento maior vinha de sua esposa (Morelli et al., 2013). Assim, mostra-se um pai dotado de recursos para pensar sobre a própria dor, delegando à mulher o papel de maior ligação emocional com o filho e, portanto, identificando-a como a pessoa que mais necessitaria de ajuda psicológica. No entanto, a esposa não residia na mesma cidade em que era realizado o tratamento do filho, de modo que não pôde receber ajuda da equipe de cuidados paliativos, a partir de intervenções especialmente voltadas aos familiares de pacientes com condições crônico-degenerativas.

Os casais 4 e 5, que também passaram por internação hospitalar devido ao aborto espontâneo (casal 4) e ao adoecimento do filho recém-nascido por pneumonia (casal 5), não relataram que receberam apoio dos serviços de saúde no sentido da oferta de um espaço de reflexão, instilação de esperança e acolhimento da dor. Assim, um primeiro elemento do aconselhamento psicológico deve ser o acolhimento desses casais na urgência da dor, em pronto-atendimento psicológico de emergência (Souza et al., 2009), tanto na preparação para a morte, como ocorre nos cuidados paliativos, quanto no momento em que os filhos adoecem e evoluem a óbito.

Os serviços de saúde geralmente contam com psicólogos e equipes aptas a acolherem esses familiares, 
mas é importante que seja configurada uma intervenção de caráter perene e que atenda às pessoas em diferentes fases do luto e também em distintas situações de perda. A configuração do atendimento psicológico deve atender à demanda existente, quer seja no tratamento de um paciente com doença crônica ou em situação de emergência. $\mathrm{O}$ aconselhamento psicológico mostrase adequado por ser uma modalidade de atendimento que, apesar de possuir elementos semelhantes aos da psicoterapia, ancora-se em técnicas específicas. Estas podem proporcionar ao enlutado um acolhimento inicial do seu sofrimento, o que lhe permite reorganizarse internamente, não excluindo a importância de que esse familiar possa ser acompanhado em atendimento psicoterápico posteriormente, a depender do grau de sofrimento emocional que experimenta e das condições psíquicas do familiar.

Assim, há que se constituir uma forma de acolher esses familiares, com aceitação incondicional de suas individualidades e respeito irrestrito às particularidades de cada caso. Nesse sentido, nem sempre as intervenções grupais mostram-se efetivas, haja vista que nem sempre há uma demanda para a composição desses grupos nem elementos suficientes para que seja composto um grupo de familiares, ainda que se formem grupos abertos e heterogêneos. As intervenções individuais podem seguir uma estratégia de atendimento breve, com foco na solução dos problemas e no acolhimento inicial do sofrimento. $\mathrm{O}$ aconselhamento psicológico pode ser desenvolvido em um ou mais encontros, a depender da necessidade e da disponibilidade do familiar, sendo uma estratégia de atendimento que visa a fornecer informações sobre o óbito, acolher a dor do familiar e ajudá-lo a desenvolver estratégias de enfrentamento e reorganização da rotina após a perda.

O processo de aconselhamento psicológico deve ser suficientemente amplo e generalista, a fim de atender a demandas distintas. No contexto hospitalar, por exemplo, a tarefa do psicólogo é a de acolhimento e humanização, sendo o seu método a escuta e a fala, que conduzem o paciente e a família a novas percepções e sensações (Domingues et al., 2013). Como exemplo extraído do presente estudo, pode-se estender essa possibilidade de escuta e fala a pais e cuidadores que acompanham pacientes crônicos, bem como a familiares que perderam seus filhos em situações traumáticas tais como os acidentes e desastres, de pessoas que passam pela internação em unidades de tratamento intensivo, entre outras possibilidades. Deve acolher casais que perdem seus filhos por aborto espontâneo e também nos primeiros dias ou meses de vida, o que pode intensificar o sofrimento de jovens casais. Nesse sentido, mais importante do que a abordagem teórica adotada, é a pronta oferta de um espaço de escuta, com intervenções que ofereçam ao enlutado o acolhimento necessário para que ele possa se reestruturar ao vivenciar seu sofrimento. A construção de um espaço como este foi descrita por Souza et al. (2009), na forma de um serviço de pronto-atendimento psicológico às pessoas que vivenciam uma perda significativa. Os resultados dessa intervenção apontaram para a importância da oferta desse serviço tanto para as pessoas que vivenciam o luto pela perda da condição de saúde ou por morte de uma pessoa significativa, como também por profissionais de saúde, que lidam constantemente com a morte e o morrer. Assim, abre-se a possibilidade de pensar no aconselhamento psicológico também voltado a esses profissionais, embora este não seja o objetivo do presente estudo.

\section{Categoria 2: Conjugalidade}

A partir da escuta dos casais que participaram do presente estudo, outro elemento foi identificado como central para compor o processo de aconselhamento com casais enlutados. Trata-se da conjugalidade. A conjugalidade, compreendida como um espaço identitário construído pelo casal, pode fornecer elementos para o enfrentamento do luto. Em muitos casos, o(a) companheiro(a) é a única fonte de apoio existente, de modo que amparar-se no parceiro pode contribuir para desenvolver ainda mais a cumplicidade, confiança e capacidade de partilhar, que fortalecem a díade conjugal. Os parceiros, embora estejam em sofrimento, podem ter mais recursos para o enfrentamento em um dado momento, podendo oferecer suporte para aquele que se encontra mais desestruturado e em intenso sofrimento (Morelli et al., 2013; Wagner \& Mosmann, 2010, 2012). Esse apoio também pode oscilar, ou seja, em alguns momentos é um determinado cônjuge que se torna capaz de oferecer maior suporte; em outros, é o outro cônjuge que assume essa posição.

No casal 4, Nayara destaca a mudança percebida na relação conjugal após a perda, apresentando a postura de maior carinho exibida pelo esposo como uma atitude compensatória, a fim de tentar diminuir a dor da esposa. Esse movimento pode ter se dado em função de que houve um aborto espontâneo e que o casal ainda planejava ter mais filhos. Desse modo, trata-se de um luto diferenciado, haja vista que uma das principais consequências para o casal foi o enlutamento em relação à expectativa da gravidez. O maior apoio à mulher pode ser justificado pelo fato de ela ser a genitora e estar experienciando a maternidade de modo aparentemente mais intenso do que o pai: 
"Mudou, mudou pelo fato que eu falei... para ele ver que eu senti que ele quis me compensar, né, de alguma forma... Ai começou, foi mais carinhoso, começou e depois se acostumou a ser mais carinhoso, mais parceiro, e está até agora, graças a Deus. Então, tem um ponto positivo." (Nayara, entrevista individual, casal 4)

Os casais 4 e 5 foram os que apresentaram de maneira mais explícita a elaboração do luto de forma coletiva (no casal) e satisfatória. A maior união foi mencionada pelo casal 5 como resultante do luto, porque precisavam se unir para ajudar a filha primogênita a lidar com o luto. Ambos concordam que amadureceram e se uniram diante da perda:

“... eu acho que serviu só pra unir mais a gente, porque a morte do Dênis [nome fictício], sei lá, trouxe mais experiência, mais firmeza pra gente, quando a gente sentava pra conversar, pra se explicar. Então, enfrentamos dificuldade financeira, a gente via a vida de uma maneira diferente. Quando você perde uma pessoa que você gosta, mediante os problemas que a gente passa nessa vida, não é nada perto da morte. Então serviu pra gente enxergar a vida de uma maneira diferente, enfrentar os problemas mais fácil, sabe que o que a gente enfrentava não era nada perto do que a gente tinha... Já passou, então serviu muito pra nos amadurecer e nos unir mais ainda." (Elisa, entrevista individual, casal 5)

A maior união do casal após vivenciarem um evento considerado traumático é considerada pela literatura científica como indicativo do processo de resiliência, que equivale à manifestação de satisfação com a vida e afetos positivos após a compreensão e elaboração da experiência dolorosa (Bonanno, Moskowitz, Papa, \& Folkman, 2005). Desenvolver a resiliência nesses casais, encorajando-os a retomarem seus projetos de vida individuais e também conjugais (como a tentativa de uma nova gestação, se este for um desejo do casal) é um dos aspectos que podem ser incorporados a programas de aconselhamento psicológico voltados a casais enlutados. Além disso, a conjugalidade é um espaço potencial no qual os cônjuges podem se sentir acolhidos e fortalecidos, sendo o casamento uma potência positiva para a superação e a transformação, ou seja, para a resiliência diante de eventos estressores e traumáticos.

Esse processo pode ser evidenciado no casal 4, que relatou que a ajuda do esposo fortaleceu a esposa para que eles tentassem uma nova gestação após a perda. A possibilidade de um novo filho foi gerada nesse espaço conjugal de acolhimento, compreensão e ressignificação do sofrimento - no caso, mais relacionado à mãe. A nova gestação não foi narrada apenas como forma de experienciar a parentalidade no casal, mas a díade revelou que a construção dessa possibilidade decorreu do relacionamento amoroso, da intimidade e da segurança emocional oferecida pelos parceiros. Desse modo, as intervenções em aconselhamento desempenham um papel fundamental junto a essas famílias, no sentido de prevenir traumas futuros e evitar o luto patológico e gravidezes reparadoras (Muza et al., 2013). O mesmo poderia ter ocorrido com o casal 5, que perdeu o filho nos primeiros dias de vida.

No casal 2, ambos superaram o luto no plano conjugal utilizando da religiosidade como forma de superação. Destacam a importância da confiança um no outro como fonte de recurso de enfrentamento. Assim, o parceiro conjugal é uma pessoa que pode se solidarizar com o sofrimento, pois também o experimenta em relação à parentalidade:

"Aquilo que falei pra você no começo, dá uma impressão de que ele queria segurar minha barra e eu a dele, e a gente ia se segurando os dois. Fomos superando os dois juntos." (Maria, entrevista com o casal, casal 2)

Maria relata que ela e o esposo se uniram mais ainda após a perda e acrescenta que extraíram um "bem eterno" da experiência traumática. Ao usar essa expressão, concebe-se que conseguiram ressignificar gradualmente o evento doloroso, de modo a contribuir para o desenvolvimento na dimensão individual e matrimonial:

“Eu creio que, aquilo que eu te falei no começo: desse sofrimento nós tiramos um bem eterno, tiramos um bem sim de todo sofrimento..." (Maria, entrevista com o casal 2)

Seja qual for o caso, a conjugalidade deve ser analisada pelo conselheiro como uma instância que, se preservada e fortalecida, pode compor a base de algumas intervenções psicológicas. Nesse sentido, o "eu" conjugal (Féres-Carneiro, 1998) pode ser fortalecido pela criação de um espaço de acolhimento no qual os cônjuges compartilham o sofrimento que incide sobre o par e criam, juntos, estratégias para a superação desse momento de dor. As intervenções em aconselhamento psicológico devem estar atentas a esses elementos, assim como o modo como a 
parentalidade foi construída por cada cônjuge, a fim de balizar estratégias de escuta e acolhimento que sejam efetivas nessa fase em que se encontram essas famílias.

\section{Categoria 3: Religiosidade}

Outro elemento de importância capital, de acordo com os pais enlutados, é a espiritualidade/religiosidade, compreendida como adesão a qualquer crença religiosa na qual o casal possa se sentir sustentado diante do sofrimento intenso despertado, no caso, pela morte de um filho. As características do apoio proporcionado pela religião ultrapassam o fornecimento de explicações mundanas para a morte e compreendem também a ajuda para que o casal se fortaleça durante o processo de luto. Acreditar em uma dimensão espiritual foi indicado pelos casais como um recurso que contribuiu para que eles aceitassem a espinhosa condição de enlutados e, de certa forma, se tornassem mais calmos e pacientes diante das repercussões desencadeadas pelos eventos vitais.

A espiritualidade/religiosidade também foi reconhecida nesses casais como uma fonte geradora de explicações acerca da morte e da perda prematura dos filhos, bem como um recurso de apoio ao longo do ciclo vital do filho e das dificuldades experienciadas por e com ele. Um exemplo é o casal 1, no qual um complicador apontado no luto de Fátima é a ambiguidade que a fatalidade trouxe. A participante sente-se conformada, pois se preocupava muito com o filho por suspeita de seu envolvimento com drogas, mas também se culpa por pensar assim e pelas orações frequentes que fazia. O conteúdo mais evocado da oração refere-se ao pedido que ela fazia reiteradamente de que seria melhor perdê-lo para Deus do que perdêlo para as drogas. Quando esse desejo se concretizou, emergiu o sofrimento suscitado pela culpa inconsciente:

"E a gente sempre lutou pro melhor pra ele, então é onde que a gente se conforma mais, é... eu ficava, semprefalava pra Deus: 'Deus, não deixa eu perder meu filho para uma cadeia e pelas drogas', sempre eu pedia pra Deus, implorava, ajoelhava na frente da Nossa Senhora, ai ele se foi desse jeito, né. Deus achou melhor pra mim e pra ele, meu sofrimento tava demais. Entrei em depressão também. Fui no hospital tomar remédio porque eu não me conformava com aquilo que tava acontecendo." (Fátima, entrevista individual, casal 1)

O aconselhamento psicológico não pode desconsiderar a dimensão da experiência espiritual/ religiosa, caso seja relatada pelos enlutados. A consideração positiva em relação à fé e à prática religiosa deve compor o rol de técnicas e estratégias desenvolvidas no âmbito do aconselhamento a enlutados. Não se trata de concordar ou discordar das crenças religiosas professadas pelos familiares, mas de utilizá-las, caso sejam mencionadas pelos familiares em atendimento, como fontes de apoio e como recurso valioso na compreensão e elaboração do processo de luto. Os profissionais devem ser sensíveis a essa escuta, promovendo um atendimento pautado nos diversos componentes trazidos pelos enlutados acerca de sua relação com o sagrado. Assim, deve-se operar uma suspensão tanto no juízo de realidade (essas práticas espirituais/religiosas são verdadeiras?) como de juízo moral (essas práticas espirituais/religiosas realmente oferecem suporte aos enlutados?), promovendo uma escuta interessada nas ressonâncias dessas práticas e preceitos na evolução desses clientes e, sobretudo, no acolhimento inicial diante da morte de alguém próximo, no caso, do filho. Algumas religiões, como destacado pelos entrevistados, possuem uma frente de apoio às pessoas enlutadas, promovendo orações, acompanhamentos e visitas constantes às pessoas que perderam pessoas próximas. Nesse sentido, tais práticas não podem ser desconsideradas em um processo no qual se busca conhecer o paciente e oferecer-lhe apoio psicológico.

Por fim, considera-se a possibilidade de que os casais enlutados também sejam atendidos de forma conjunta, o que pode potencializar a situação de conjugalidade como fonte de recursos para enfrentamento dos desafios impostos pelo luto decorrente da perda de um filho. $\mathrm{O}$ acolhimento conjunto aos pais enlutados pode ser um modo de oferecer não apenas a escuta, mas também o apoio efetivo do parceiro, desde que ele esteja presentificado e disponível para assumir a atitude de ajuda. Os atendimentos podem ser oferecidos em espaços individuais, para que cada cônjuge se sinta confortável para narrar sua experiência particular, mesclando as intervenções com o uso desses espaços nos quais o casal pode se expressar enquanto díade, recuperando elementos da conjugalidade e da parentalidade que se mostram importantes na elaboração saudável da experiência de luto.

$\mathrm{O}$ apoio do parceiro pode se revelar de modo mais direto nesses cenários em que o casal é instituído como foco de intervenção. Assim, os elementos aqui mencionados, delineados a partir da compreensão das experiências dos casais, devem contribuir para estruturar modelos de intervenção, a fim de que se possam ponderar os limites e as potencialidades do atendimento em aconselhamento psicológico no campo do enlutamento, oferecendo suporte a estudos que 
buscam avaliar a eficácia dessas práticas psicológicas na promoção do bem-estar e do ajustamento (Larson \& Hoyt, 2007).

\section{CONSIDERAÇÕES FINAIS}

Ao final do percurso empreendido neste estudo conclui-se que são diversos os eventos que, na experiência do luto, repercutem sobre o desenvolvimento pessoal e matrimonial dos cônjuges. Percebeu-se que a extensão e intensidade do impacto dependem dos complicadores envolvidos. Confirmouse a hipótese, nos casais participantes, de que a morte do ente querido modifica o casamento, assim como o nascimento dos descendentes e a oficialização da união, exigindo uma restauração das forças vivas que organizam a dinâmica conjugal e familiar.

O luto tem impacto disruptivo na dinâmica conjugal e ameaça o equilíbrio do par. Nota-se que cada casal apresentou uma maneira singular de enfrentar o processo de luto que, consequentemente, trouxe implicações ao casamento. Os modos de enfrentamento dos casais participantes foram influenciados por diversos fatores em vigor, mecanismos próprios, espólios de legados inconscientes transgeracionais, circunstâncias específicas do falecimento, união conjugal, auxílio recebido, entre outros, aspectos estes que devem ser considerados no processo de aconselhamento psicológico.

Nenhum dos enlutados contou com auxílio profissional durante o percurso de luto. A importância do atendimento a essas famílias é destacado por Muza et al. (2013), que consideram que esse intenso trabalho psíquico de luto ainda recebe pouco apoio social das instituições de saúde, por exemplo. Em um processo chamado de educação para a morte, Kovács (2005) salienta que os profissionais que lidam com a temática da morte devem constantemente discutir em seus programas de aperfeiçoamento assuntos como preparação para a morte, comunicação, relacionamentos, situações-limite, perda de pessoas significativas, doenças, acidentes, até o confronto com a própria morte. Diante da escassez de ajuda profissional, os enlutados recorrem a contextos religiosos, rede de amigos e familiares, e ao próprio companheiro. Não se trata, aqui, de defender a intervenção psicológica em detrimento de outras práticas, mas de enfatizar a necessidade de que essa ajuda profissional possa estar a serviço dos familiares que a desejarem e demandarem esse espaço de escuta, o que vem sendo avaliado como efetivo na literatura científica (Larson \& Hoyt, 2007). É preciso considerar, ainda, que esse apoio profissional não precisa ocorrer necessariamente em hospitais, como destacado na maior parte da literatura (Domingues et al., 2013; Muza et al., 2013), mas também em centros comunitários, organizações não governamentais e demais espaços de socialização.

No que se refere especificamente ao apoio conjugal, há que se destacar que, se o cônjuge não estiver apto para apoiar, pode precipitar uma crise conjugal, sentimento de inadequação, culpa inconsciente, falta de compreensão, sentimento de solidão, desamparo e tristeza. A atmosfera protetora instilada pelas entrevistas realizadas neste estudo ofereceu um espaço de escuta para esses casais que até então pouco puderam falar a respeito de seu sofrimento. Assim, o estudo constituiu um espaço privilegiado para a exposição de angústias, o que se mostrou importante ao considerar as necessidades psicológicas experienciadas pelo casal nesse processo. Ao ouvir individualmente cada cônjuge em um primeiro momento e, posteriormente, o casal, recuperou-se a necessidade de que cada cônjuge não apenas ouça seu parceiro em seu sofrimento, como lhe ofereça suporte em seus questionamentos e em sua dor. Existe, claramente, um pedido latente de ajuda por parte de alguns indivíduos enlutados, o que pode ser balizador de intervenções profissionais, como é o caso do aconselhamento psicológico destacado neste estudo.

A partir desses elementos, abre-se a possibilidade de desenvolver um programa de intervenção em aconselhamento psicológico voltado a pais enlutados. Os atendimentos breves e em casal podem contribuir para que a conjugalidade seja compreendida não apenas como uma dimensão diretamente afetada pela perda do filho, mas que possa também configurar-se em um espaço de construção conjunta de estratégias de enfrentamento e de facilitação de diálogos sobre o processo de enlutamento. Intervenções interessadas em fortalecer a conjugalidade podem promover formas menos estereotipadas de atendimento, em que o foco não está no luto ou na perda em si, mas no casal como fonte de apoio mútuo e recurso prioritário para o enfrentamento da situação. Conforme sugerido em alguns estudos (Currier et al., 2008; Larson \& Hoyt, 2007; Sandler et al., 2003), a avaliação da eficácia dessas intervenções no longo prazo deve ser um dos aspectos a ser considerado pelos profissionais do aconselhamento psicológico.

Embora os elementos discutidos neste estudo possam balizar futuras intervenções, um dos limites da investigação é não ter operacionalizado um processo de aconselhamento psicológico com os pais participantes. No entanto, compreendemos que o processo de escuta desses casais, embora tenha sido breve e tenha cumprido os requisitos de uma entrevista de coleta de dados, parece ter possibilitado um acolhimento 
inicial de certas necessidades silenciosas desses cônjuges. Nessa vertente, dar voz e compreender as experiências desses casais é uma etapa imprescindível para o delineamento preliminar de qualquer proposta de atendimento individual ou em casal.

\section{REFERÊNCIAS}

Alves, D., Fernández-Navarro, P., Ribeiro, A. P., Ribeiro, E., \& Gonçalves, M. M. (2014). Ambivalence and innovative moments in grief psychotherapy: The cases of Emily and Rose. Psychotherapy, 51(2), 308-321.

Bittencout, A. L. P., Quintana, A. M., \& Velho, M. T. A. C. (2011). A perda do filho: Luto e doação de órgãos. Estudos de Psicologia (Campinas), 28(4), 435-442.

Bolze, S. D. A. \& Castoldi, L. (2005). O acompanhamento familiar antes e depois da morte da criança: Uma proposta de intervenção para o psicólogo hospitalar. Aletheia, 21, 79-91.

Bonanno, G. A., Moskowitz, J. T., Papa, A., \& Folkman, S. (2005). Resilience to loss in bereaved spouses, bereaved parents, and bereaved gay men. Journal of Personality and Social Psychology, 88(5), 827-843.

Bowlby, J. (1985). Perda: Tristeza e depressão (Valtensir Dutra, Trad.). São Paulo: Martins Fontes.

Dennis, M. R. \& Kunkel, A. (2012). Relationship after loss: Communication in the new grief paradigm. In O. Gillath, G. Adams, \& A. Kunkel (Eds.). Relationship science: Integrating evolutionary, neuroscience, and sociocultural approaches (pp. 199-218). Washington, DC, US: American Psychological Association.

Domingues, G. R., Alves, K. O., Carmo, P. H. S., Galvão, S. S., Teixeira, S. S., \& Baldoino, E. F. (2013). A atuação do psicólogo no tratamento de pacientes terminais e seus familiares. Psicologia Hospitalar, 11(1), 2-24.

Féres-Carneiro, T. (1998). Casamento contemporâneo: O difícil convívio da individualidade com a conjugalidade. Psicologia: Reflexão e Crítica, 11(2), 379-394.

Ferreira, R. A., Lira, N. P. M., Siqueira, A. L. N., \& Queiroz, E. (2013). Percepções de psicólogos da saúde em relação aos conhecimentos, às habilidades e às atitudes diante da morte. Psicologia: Teoria e Prática, 15(1), 65-75.

Forghieri, Y. C. (2007). Aconselhamento terapêutico: Origens, fundamentos e prática. São Paulo: Thomson Learning.

Freud, S. (1976). Sobre o narcisismo: Uma introdução. In S. Freud, Obras Psicológicas Completas de Sigmund Freud: Volume XIV (pp. 75-83) (J. Salomão, Trad.). Rio de Janeiro: Imago. (Original publicado em 1914).

Gonçalves, M. O. (2001). Morte e castração: Um estudo psicanalítico sobre a doença terminal infantil. Psicologia: Ciência e Profissão, 21(1), 30-41.

Kovács, M. J. (1992). Morte e desenvolvimento humano. São Paulo: Casa do Psicólogo.

Kovács, M. J. (2005). Educação para a morte. Psicologia: Ciência e Profissão, 25(3), 484-497.

Kovács, M. J. (2012). Educadores e a morte. Psicologia Escolar e Educacional, 16(1), 71-81.

Larson, D. G. \& Hoyt, W. T. (2007). What has become of grief counseling? An evaluation of the empirical foundations of the new pessimism. Professional Psychology: Research and Practice, 38(4), 347-355.
Magagnin, C., Kõrbes, J. M., Hernandez, J. A. E., Cafruni, S., Rodrigues, M. T., \& Zarpelon, M. (2003). Da conjugalidade à parentalidade: Gravidez, ajustamento e satisfação conjugal. Aletheia, 17/18, 41-52.

Magalhães, A. S. \& Féres-Carneiro, T. (2004). Transmissão psíquico-geracional na contemporaneidade. Psicologia em Revista, 10(16), 243-255.

Meihy, J. C. S. B. \& Holanda, F. (2010). História oral: Como fazer, como pensar. São Paulo: Contexto.

Menezes, C. C. \& Lopes, R. C. S. (2007). A transição para o casamento em casais coabitantes e em casais não-coabitantes. Revista Brasileira de Crescimento e Desenvolvimento Humano, 17(1), 52-63.

Minayo, M. C. S. (2006). O desafio do conhecimento: Pesquisa qualitativa em saúde. ( $9^{\mathrm{a}}$ ed.). São Paulo: Hucitec.

Monti, M. R. (2008). Contrato narcisista e clínica do vazio. Revista Latinoamericana de Psicopatologia Fundamental, 11(2), 239-253.

Morato, H. T. P. (Org.) (1999). Aconselhamento psicológico centrado na pessoa: Novos desafios. São Paulo: Casa do Psicólogo.

Morelli, A. B., Scorsolini-Comin, F., \& Santos, M. A. (2013). Impacto da morte do filho sobre a conjugalidade dos pais. Ciência \& Saúde Coletiva, 18(9), 2711-2720.

Muza, J. C., Sousa, E. N., Arrais, A. R., \& Iaconelli, V. (2013). Quando a morte visita a maternidade: Atenção psicológica durante a perda perinatal. Psicologia: Teoria e Prática, 15(3), 34-48.

Pascoal, M. (2012). Trabalho em grupo com enlutados. Psicologia em Estudo, 17(4), 725-729.

Peres, R. S. \& Santos, M. A. (2005). Considerações gerais e orientações práticas acerca do emprego de estudos de caso na pesquisa científica em Psicologia. Interações, 20(10), 109-126.

Sandler, I. N., Ayers, T. S., Wolchik, S. A., Tein, J., Kwok, O., Haine, R. A. et al. (2003). The family bereavement program: Efficacy evaluation of a theory-based prevention program for parentally bereaved children and adolescents. Journal of Consulting and Clinical Psychology, 71(3), 587-600.

Santos, O. B. (1982). Aconselhamento psicológico \& psicoterapia: auto-afirmação - um determinante básico. São Paulo: Pioneira.

Santos, E. M., \& Sales, C. A. (2011). Familiares enlutados: Compreensão fenomenológica existencial de suas vivências. Texto \& Contexto Enfermagem, 20(n. esp.), 214-222.

Schmidt, M. L. S. (2012). O nome, a taxonomia e o campo do aconselhamento psicológico. In H. T. P. Morato, C. L. B. T. Barreto, \& A. P. Nunes (Orgs.), Aconselhamento psicológico numa perspectiva fenomenológica existencial (pp. 1-21). Rio de Janeiro: Guanabara Koogan.

Scorsolini-Comin, F. (2014). Aconselhamento psicológico e psicoterapia: Aproximações e distanciamentos. Contextos Clínicos, 7(1), 2-14.

Scorsolini-Comin, F. \& Santos, M. A. (2011). Casamento e satisfação conjugal: Um olhar da Psicologia Positiva. São Paulo: Annablume/FAPESP; Brasília: CNPq.

Scorsolini-Comin, F. \& Santos, M. A. (2013). Counseling Psychology: A view of the scientific production in the Brazilian postgraduation. Revista Brasileira de Crescimento e Desenvolvimento Humano, 23(3), 338-345.

Silva, A. C. O. \& Nardi, A. E. (2010). Luto pela morte de um filho: Utilização de um protocolo de terapia cognitivo-comportamental. Revista de Psiquiatria do Rio Grande do Sul, 32(3), 113-116. 
Souza, A. M., Moura, D. S. C., \& Corrêa, V. A. C. (2009). Implicações do pronto-atendimento psicológico de emergência aos que vivenciam perdas significativas. Psicologia: Ciência e Profissão, 29(3), 534-545.

Wagner, A. \& Mosmann, C. P. (2010). Educar para a conjugalidade: Que a vida não nos separe. In L. C. Osório \& M. E. P. Valle (Orgs.). Manual de terapia familiar (Vol. 2; pp. 261-270). Porto Alegre: Artmed.

Wagner, A. \& Mosmann, C. P. (2012). Intervenção na conjugalidade: Estratégias de resolução de conflitos conjugais. In M. N. Baptista, \& M. L. M. Teodoro (Orgs.). Psicologia de família: Teoria, avaliação e intervenção (pp. 240-248). Porto Alegre: Artmed.

Este estudo foi financiado pelo Conselho Nacional de Desenvolvimento Científico e Tecnológico (CNPq).
Autores:

Ana Bárbara Morelli - Graduanda do curso de Psicologia da Universidade Federal do Triângulo Mineiro (UFTM).

Fabio Scorsolini-Comin - Professor Adjunto do Departamento de Psicologia da Universidade Federal do Triângulo Mineiro (UFTM). Doutor em Psicologia pela Universidade de São Paulo (FFCLRP-USP).

Manoel Antônio dos Santos - Professor Associado da Faculdade de Filosofia, Ciências e Letras de Ribeirão Preto da Universidade de São Paulo (FFCLRPUSP).

Endereço para correspondência:

Fabio Scorsolini-Comin

Departamento de Psicologia

Universidade Federal do Triângulo Mineiro

Centro Educacional

Av. Getúlio Guaritá, 159 - Abadia

CEP 38025-440 Uberaba, MG, Brasil

E-mail: scorsolini_usp@yahoo.com.br

Recebido em: 15.04 .14

Aceito em: 11.09.14. 